\title{
Workshop: Making a Technical Argument - Teaching Technical Analysis and Communication together
}

\author{
Sunny Bains \\ University College London \\ sunny.bains@ucl.ac.uk
}

\begin{abstract}
This workshop describes a technical argument template that can be used in many different situations where engineers need to write a straightforward technical report. It is ideal for situations when a new solution is being recommended, the value of a piece of work (or new product) has to be explained, or when several solutions need to be compared. However, it can also be adapted for many other circumstances, such as reviews articles, proposal, and pitches. The structure embeds critical thinking about the technology or solution being discussed and, more importantly, what it is intended to achieve. Crucially, it focusses on the early argument steps (the ones that engineers often neglect in their rush to get to the technical detail), rather than the straightforward description of the solution itself (which technical people generally discuss straightforwardly without assistance).
\end{abstract}

Index Terms - Technical argument, vision, analysis, comparative technology, writing, presentation.

\section{AUDIENCE}

Though the primary audience will be teachers and trainers of technical communication, this workshop will be useful for anyone who has been looking for a consistent and logical formula for making technical arguments. This would include everyone from students and young engineers, technical management, research supervisors, technical press/public relations professionals, and more.

\section{LEARNING OUTCOMES}

To teach both critical thinking and communication to engineering students, we use a template that steps the student through the steps of a technical argument [1]. By asking the students to use these steps, we are pushing them to engage with several issues that are critical to both the research and communication process: thinking about the context of an engineering (or scientific solution), how the criteria by which any solution will be judged, and how the audience they are trying to address is best engaged with the subject. The steps in this argument are as follows.

Vision: Why does the technical issue being discussed matter to the audience?

Status Quo: How were things done before the new approach? Why wasn't that good enough?

Technical Problem: What is the technical issue preventing progress?

Competing solutions: Who else is working on this, what are they doing, and why isn't it good enough?

New/Proposed Solution: What is it, how was it designed, how does it work, how well does it work?

Obstacles: Why might it fail? What further work needs to be done?

Discussion/Prognosis: How does this solution compare with the others, and what is the future likely to be?

In the workshop, we will explain each of these in detail, show how they can be used to craft a report, and highlight how they can provide a common vocabulary to help as part of the editing/teaching process.

After attending this workshop, participants should be able to:

- Use a common vocabulary to discuss specific features in technical arguments;

- Explain the role of each of these features, both in technical and explanatory terms;

- Analyze an argument based on these features.

\section{ACTIVITIES}

A critical part of understanding the argument structure is to see it both correctly and incorrectly applied. Within the 75 minutes we will look at two pieces of technical journalism (ideal because it is shorter and more readable than the technical literature). Neither will be perfect, but by analyzing the structure of the argument in each one, 
students will learn to be able to both identify the elements, and to understand why their order is so important. Students will read the article, identify the elements and - crucially - discuss how the articles could be improved by further explanation and/or better organization. Where participants are willing and have appropriate technical stories to discuss, we will also ask them to use the formula to explain their own work, and, in masterclass style, show how to hone the message so that it is both clear and persuasive.

\section{REFERENCES}

[1] S. Bains, Explaining the Future: How to Research, Analyze, and Report on Emerging Technologies. Oxford University Press, 2019.

\section{ABOUt THE Author}

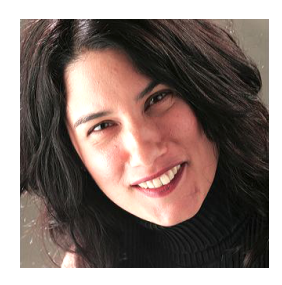

Sunny Bains is a Principal Teaching Fellow at University College London, in the Department of Biochemical Engineering, author of Explaining the Future: How to Research, Analyze, and Report on Emerging Technologies, and Editorial Director of Engineering Inspiration http://engins.org. She has two decades experience as a technical journalist and editor (for The Economist, New Scientists, Science, Wired, EE Times, Laser Focus World, and many others), and another two teaching at the University of California at Berkeley, Imperial College London, and UCL. She has a BSc in Physics (Queen Mary, University of London, 1990), an MS in Journalism (Boston University, 1994), and a PhD on Physical Computation and Embodied Artificial Intelligence (Open University, 2005). She teaches research, analysis and communication skills to students at various levels across engineering and the physical sciences. 